\title{
Impact of Wind Speed on Response of Diffusion-Type Radon-Thoron Detectors to Thoron
}

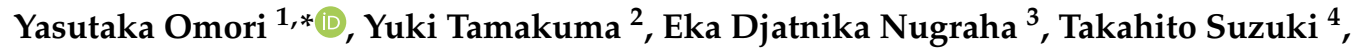 \\ Miki Arian Saputra ${ }^{3}$, Masahiro Hosoda ${ }^{2,3}$ and Shinji Tokonami ${ }^{2}$ (D) \\ 1 Department of Radiation Physics and Chemistry, Fukushima Medical University, 1 Hikarigaoka, \\ Fukushima 960-1295, Japan \\ 2 Institute of Radiation Emergency Medicine, Hirosaki University, 66-1 Hon-cho, Hirosaki, Aomori 036-8564, \\ Japan; tamakuma@hirosaki-u.ac.jp (Y.T.); m_hosoda@hirosaki-u.ac.jp (M.H.); \\ tokonami@hirosaki-u.ac.jp (S.T.) \\ 3 Graduate School of Health Sciences, Hirosaki University, 66-1 Hon-cho, Hirosaki, Aomori 036-8564, Japan; \\ h20gg701@hirosaki-u.ac.jp (E.D.N.); h18gg206@hirosaki-u.ac.jp (M.A.S.) \\ 4 Fuji Electric Co., Ltd., 1 Fujimachi, Hino, Tokyo 191-8502, Japan; suzuki-takahito@fujielectric.com \\ * Correspondence: ys-omori@fmu.ac.jp; Tel.: +81-24-547-1250
}

Received: 24 March 2020; Accepted: 30 April 2020; Published: 2 May 2020

\begin{abstract}
Air exchange through a porous medium depends partly on a pressure gradient induced in it, i.e., air-flow conditions of the outer air. Consequently, response of diffusion-type detectors to radon and thoron may vary with air-flow conditions surrounding the detectors. This effect may be significant for thoron measurement because thoron has a shorter half-life than radon. The present study examined response of diffusion-type detectors (RADUETs and one AlphaGUARD) to thoron with respect to wind speed using a thoron calibration chamber. Response of RADUETs to thoron increased with wind speed. Response of the AlphaGUARD increased with wind speed, but it became constant at a high wind speed. Different response trends to thoron between the RADUETs and the AlphaGUARD could be qualitatively explained by flow states induced by the pressure gradient in the filter or the sponge of these detectors. For RADUETs, laminar (Darcy) flow was induced in the sponge in the examined wind speed range, which meant that thoron entry into the detector increased with wind speed. For the AlphaGUARD, laminar flow was induced in the filter in the low wind speed range, whereas flow was changed to turbulent (non-Darcy) flow at a high wind speed for which thoron entry into the detector did not depend on wind speed.
\end{abstract}

Keywords: advection; air exchange; Darcy flow; diffusion-type detector; laminar flow; non-Darcy flow; porous medium; radon; thoron; turbulent flow

\section{Introduction}

Gaseous radon isotopes, ${ }^{222} \mathrm{Rn}$ (radon) and ${ }^{220} \mathrm{Rn}$ (thoron), in the air are regarded as major naturally existing sources of radiation exposure to the public [1,2]. According to estimates by the United Nations Scientific Committee on the Effects of Atomic Radiation [1], annual effective doses from internal exposure to radon and thoron are $1.2 \mathrm{mSv}$ and $0.1 \mathrm{mSv}$, respectively. Although major contributors to the internal dose are their decay products, measurements of radon and thoron concentrations are effective in clarifying quantitative relationships between mother radionuclides and decay products in the living environment for use in regulation purposes (e.g., [3-9]).

The present study focuses on thoron measurement, which is of significance in two points of radiological protection. The first is to assess the internal dose from thoron. Although the dose from thoron is low, it can become a dominant (non-negligible) component for occupants in certain types 
of dwellings (e.g., cave dwellings, clay dwellings) and dwelling locations (e.g., on monazite-rich land), and thoron concentration should be measured along with radon concentration (e.g., [10-15]). The second point is to contribute to reliable measurement of radon concentration. Radon detectors without a function for alpha-energy discrimination have some response to thoron (e.g., [16,17]). If such detectors are used in an environment with both radon and thoron, such as what is generally seen in a natural environment, thoron is measured as "radon" (namely, thoron interferes with the radon measurement). To minimize thoron interference, radon concentration is corrected using thoron concentration, which is simultaneously measured (e.g., by using twin-cup radon and thoron detectors).

Diffusion-type radon and thoron detectors have been used widely for long-term measurements of radon and thoron concentrations to assess inhalation dose (e.g., [18-20]). Diffusive entry (i.e., natural air exchange) is employed to sample the air inside the detection volume of the detectors. Air inlets of the detectors are covered with filters or sponges to prevent ambient aerosols including decay products of radon and thoron from infiltrating into the detection volume. Properties of filters or sponges affect the air exchange rate through them. Previous studies formulated the air exchange rate $(\gamma)$ as follows [18,21,22]:

$$
\gamma=\frac{\mathrm{D}_{\mathrm{p}} \mathrm{A}}{d \mathrm{~V}}
$$

where $D_{p}$ is diffusion coefficient in a porous medium such as a filter or a sponge (hereinafter filter/sponge), $d$ is thickness of the medium, $\mathrm{A}$ is area of the air inlet(s), and $\mathrm{V}$ is volume of the detector. The diffusion coefficient is constrained by air temperature and porosity and tortuosity of the medium. Changes in the air exchange rate affect the response of the detectors to radon and thoron. Especially, the effect on response would be directly significant for thoron measurement, because thoron has a shorter half-life (55.6 s) than radon has (3.8 d) and thoron entry through a porous medium into the detectors depends largely on the air exchange rate. Indirectly, radon measurement also would be affected because the radon concentration is sometimes corrected by using thoron concentration to minimize thoron interference on the radon measurement. Thus, it is quite important to clarify factors changing the air exchange rate of diffusion-type detectors.

Previous studies have indicated the change in the air exchange rate associated with the diffusion process in a porous medium. Fleischer et al. [23] reported increased permeability of radon through a membrane filter with increase of the membrane temperature. Similar temperature dependence was obtained for polyethylene polymer foils [24]. Sorimachi et al. [25] reported decreased response of a diffusion-type detector to thoron with increased relative humidity. In addition to these studies, it was recently proposed that the air exchange process was controlled by advection as well as diffusion. Omori et al. [26] found changes in the response of a diffusion-type detector to thoron according to the presence and the absence of forced ventilation of the air surrounding the detector. These authors pointed out the possible induction of advective flow through the filter of the detector caused by the forced air ventilation, and they modified Equation (1) to express the air exchange rate, which is linked to the response to thoron, as follows:

$$
\gamma=\frac{A}{V}\left(\frac{D_{\mathrm{p}}}{d}+u\right)
$$

where $u$ is air velocity induced by the pressure gradient in the filter. However, the potential effect of the induced advective flow on the change in the air exchange rate remains unclear. This is because the experiment was conducted in the environment, which showed low thoron concentrations of 10-100 Bq $\mathrm{m}^{-3}$ with diurnal fluctuations and, consequently, the distribution of the estimated response to thoron was wide [26]. Moreover, only one detector was used for the experiment under the condition with and without the air ventilation. It has not been clarified whether the change in the air exchange rate with respect to wind speed depends on characteristics of detectors.

The present study aims at examining changes in the response of two diffusion-type detectors to thoron (linked to the air exchange rate) against a wide range of wind speeds in more detail than the previous study did [26]. For exposure of the detectors to thoron, a thoron calibration chamber was 
used to control thoron concentration stably at the orders of $1000-10,000 \mathrm{~Bq} \mathrm{~m}^{-3}$ and also to control wind speed.

\section{Materials and Methods}

\subsection{Detectors}

Diffusion-type detectors examined in the present study were the solid state nuclear track detectors enclosed in diffusion chambers, marketed as RADUETs (Radosys, Ltd., Budapest, Hungary), and a pulse-ionization chamber, marketed as the AlphaGUARD PQ2000Pro (Saphymo GmbH, Frankfurt, Germany; hereinafter the AlphaGUARD PQ2000Pro is just called the AlphaGUARD) (Figure 1). The former are passive-type radon-thoron discriminative detectors, whereas the latter is an active radon detector that is able to run in the diffusion mode. The AlphaGUARD is typically used to measure radon concentration, but it has a sensitivity to thoron (e.g., $[17,26-31])$ because it does not have a function to discriminate between radon and thoron. In the present study, the AlphaGUARD was used to examine thoron entry into the detector diffusion chamber, which is also useful to clarify thoron interference for radon measurement (Figure 1).
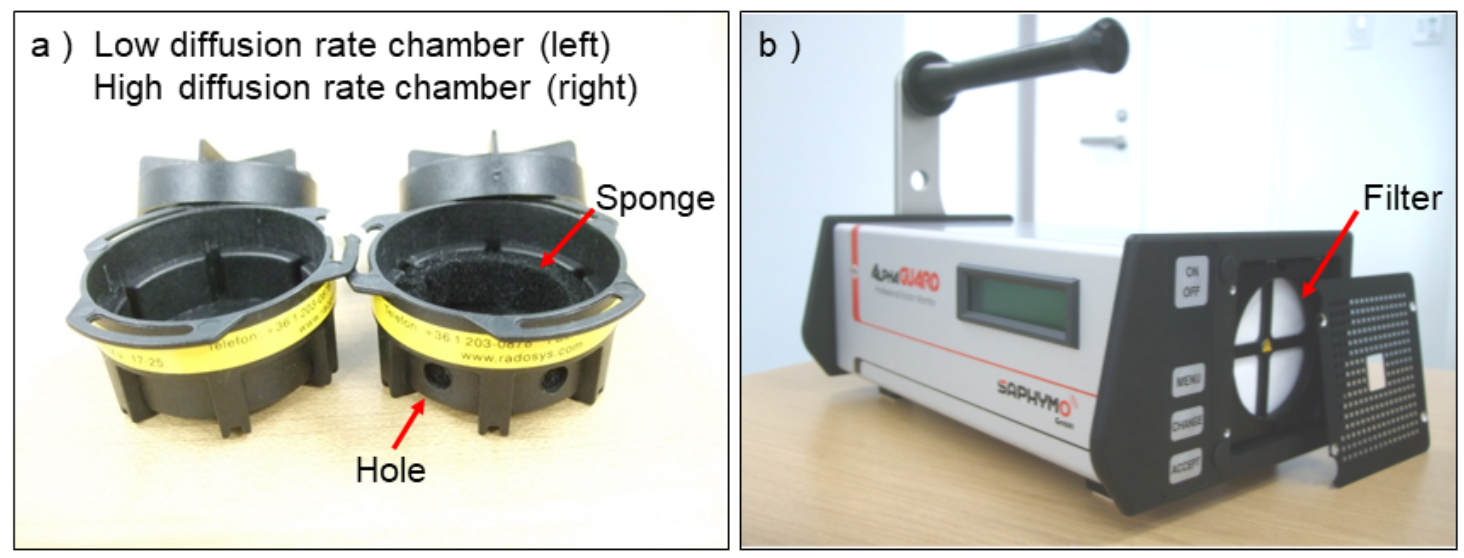

Figure 1. Views of the detectors examined in the present study: RADUET (a) and AlphaGUARD (b).

Each RADUET consists of two diffusion chambers with different air exchange rates and a solid-state nuclear track detector CR-39 (BARYOTRAK, Nagase Landauer, Ltd., Ibaraki, Japan) enclosed in each chamber $[19,25,32]$. The two diffusion chambers are made of electro-conductive plastic with an inner volume of $3.0 \times 10^{-5} \mathrm{~m}^{3}$. The low diffusion rate chamber detects mainly radon, since there is a diffusion barrier against thoron. On the other hand, the high diffusion rate chamber detects both radon and thoron due to the configuration of the chamber, which has six evenly spaced holes in the cylindrical side wall. An electro-conductive sponge was put on the inner side wall to cover the holes, which prevented ambient aerosols including decay products of radon and thoron from infiltrating into the chamber. For this chamber, radon and thoron gases are introduced into the chamber by natural air exchange through the electro-conductive sponge. The air exchange rates of the low and high diffusion rate chambers $\left(0.71 \mathrm{~h}^{-1}\right.$ vs. $10 \mathrm{~h}^{-1}$, respectively) differ by two orders of magnitude [25,32], which enables the RADUETs to discriminate radon and thoron without alpha-ray spectrometry. In the present study, only the high diffusion rate chamber of the RADUET was examined (hereinafter RADUET refers to the device using only the high diffusion rate chamber). After exposure of the RADUETs to thoron was completed, they were processed together with control RADUETs at Fukushima Medical University (Japan) to obtain track densities formed on CR-39s. To enlarge the formed tracks, the CR-39s were etched in a $6 \mathrm{M} \mathrm{NaOH}$ solution at $60^{\circ} \mathrm{C}$ for $24 \mathrm{~h}$. The formed tracks were counted at $100 \times$ magnification with an upright microscope (ECLIPSE E100, Nikon Corporation, Tokyo, Japan) combined with image processing software, and, consequently, track densities were obtained. The details on processing CR-39 are given elsewhere $[12,13]$. 
The AlphaGUARD is a pulse-ionization chamber with a diffusion chamber with an effective volume of $5.6 \times 10^{-4} \mathrm{~m}^{3}$. It can run in the diffusion or the flow mode according to the measurement purposes. The air inlet of the diffusion chamber is circular with a $6.5 \mathrm{~cm}$ diameter, and radon and thoron gases are introduced into the chamber by natural air exchange through a glass-fiber filter covering the inlet when running in the diffusion mode. According to the manufacturer, the glass-fiber filter has a surface density of $70 \mathrm{~g} \mathrm{~m}^{-2}$, a thickness of $0.35 \mathrm{~mm}$, and an average retention capacity of $0.6 \mu \mathrm{m}$. Although the AlphaGUARD is a radon detector, it detects thoron at $0.05-0.10$ of the actual thoron concentration $[17,26,30,31]$. That is, when thoron concentration in the air increases from 0 to $100 \mathrm{~Bq} \mathrm{~m}^{-3}$, the value indicated by the AlphaGUARD in the diffusion mode increases by $5-10 \mathrm{~Bq} \mathrm{~m}^{-3}$. The AlphaGUARD examined in the present study was calibrated using a radon calibration chamber established in the National Institutes for Quantum and Radiological Science and Technology (Japan).

\subsection{Experiment}

Experiments were conducted by using a thoron calibration chamber established in Hirosaki University (Japan). The thoron calibration chamber system consists of a thoron concentration controller, thoron gas monitors, and a stainless-steel exposure chamber with an inner volume of $1.5 \times 10^{-1} \mathrm{~m}^{3}$ (dimensions: $0.60 \mathrm{~m}$ diameter and $0.52 \mathrm{~m}$ height) (Figure 2a; [33]). Commercial lantern mantles were used as the thoron source and stacked together in a cylindrical column. The thoron concentration was controlled by changing the absolute humidity in the air, which passes through the thoron source [34]. The thoron gas generated from the source was injected into the exposure chamber and mixed well by an internal direct current (DC) fan (Model 9WF1224H101, Sanyo Denki Co., Ltd., Tokyo, Japan) installed at the top of the chamber to homogenize the thoron concentration. The thoron concentrations were monitored by alpha-ray spectrometry every hour by a radon-thoron discriminative monitor (RAD7, DURRIDGE Company, Inc., Billerica, MA, USA). During exposures of the detectors to thoron, a grab sampling technique using a scintillation cell (300A, Pylon Electronics Inc., Mississauga, ON, Canada) with a portable radon monitor (AB-5, Pylon Electronics Inc.) was also applied to correct the thoron concentrations measured by the RAD7 [35].

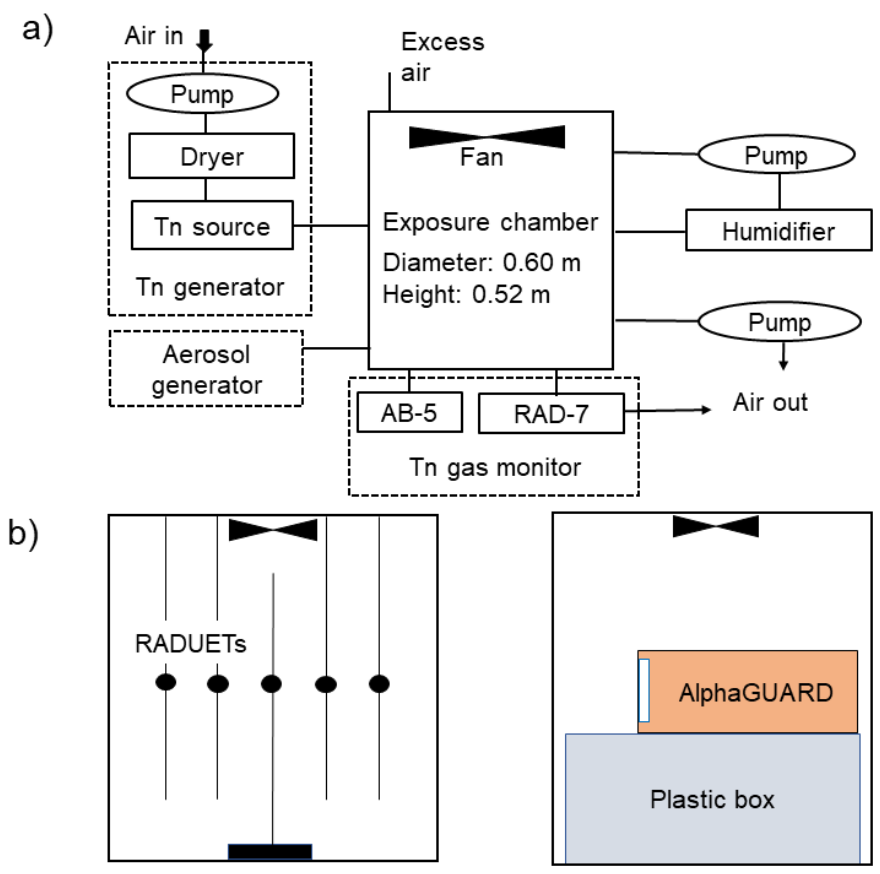

Figure 2. Schematic representations of the thoron calibration chamber system (a) and experimental setup for exposures of the RADUETs and AlphaGUARD to thoron (b). Panel (a) is modified from Pornnumpa et al. [33]. 
The detectors were set at $26 \mathrm{~cm}$ from the top and the bottom of the thoron calibration chamber (Figure 2b). For exposure of the RADUETs, five detectors were hung from the top. Thoron concentrations and exposure times were taken as $12000-16000 \mathrm{~Bq} \mathrm{~m}^{-3}$ and $70-80 \mathrm{~h}$, respectively, and, consequently, time-integrated thoron concentrations were $1000-1300 \mathrm{kBq} \mathrm{m}^{-3} \mathrm{~h}$ to reduce uncertainty of track counting with the microscope. After the exposure was completed, the CR-39s of the sampled RADUETs were processed together with those of the control RADUETs to derive net track densities due to thoron exposure. For exposure of the AlphaGUARD, it was put on top of a plastic box to set the center of the detector inlet at a $26 \mathrm{~cm}$ height. The AlphaGUARD was set to the diffusion mode with a measurement cycle of $1 \mathrm{~h}$. Thoron concentrations and exposure times were taken as 900-13,000 Bq m ${ }^{-3}$ and 1-2 d, respectively. For the analysis, successive 12-21 hourly data were used because it took $5-10 \mathrm{~h}$ for thoron concentration to become stable in the thoron calibration chamber. Before starting the exposure, radon concentrations in the room where the thoron calibration chamber was located were measured. The results were used as background concentrations to evaluate net values due to the exposure of the AlphaGUARD to thoron.

The exposures of the RADUETs and AlphaGUARD to thoron were conducted at four levels of rotational speeds of the DC fan. The rotational speed was set as very low, low, reference, and high levels. The reference level was the setting for the usual calibration purpose. The lower two levels and the reference level of the rotational speed were controlled by changing the voltage applied to the original DC fan, whereas the highest level was controlled by using another DC fan (Model 9HV1248P1G001, Sanyo Denki Co., Ltd., Tokyo, Japan). Wind speed in the thoron calibration chamber, without the RADUETs or the AlphaGUARD, was measured by using a handheld anemometer. That is, the wind measurement could not be conducted simultaneously with exposure of the detectors to thoron because of the limited space of the small thoron calibration chamber. The non-directional anemometer sensor together with a palm-size data recorder (Model 6542, KANOMAX Japan Incorporated, Osaka, Japan) was put at the $26 \mathrm{~cm}$ height in the thoron calibration chamber. Wind speed was measured both at the center and $5 \mathrm{~cm}$ from the chamber wall at the four DC-fan rotational speed levels. In each measurement, wind speed was recorded every $5 \mathrm{~s}$ for about $1 \mathrm{~min}$. The results are summarized in Table 1.

Table 1. Wind speed in the thoron calibration chamber at four rotational speed levels of direct current (DC) fans.

\begin{tabular}{cccc}
\hline \multirow{2}{*}{ Rotational Speed Level } & \multicolumn{3}{c}{ Wind Speed $\left(\mathbf{m ~ s}^{\mathbf{- 1}}\right)$} \\
\cline { 2 - 4 } & Center $^{\mathbf{1}}$ & Near Wall $^{\mathbf{1}}$ & Average $^{\mathbf{2}}$ \\
\hline Very low & $0.33 \pm 0.01$ & $0.20 \pm 0.02$ & 0.27 \\
Low & $0.75 \pm 0.02$ & $0.44 \pm 0.03$ & 0.59 \\
Reference & $0.85 \pm 0.05$ & $0.85 \pm 0.05$ & 0.85 \\
High & $1.84 \pm 0.05$ & $2.00 \pm 0.06$ & 1.92 \\
\hline
\end{tabular}

${ }^{1}$ Average value \pm one standard deviation obtained from the repeated measurements. ${ }^{2}$ Wind speed averaged at the center and near wall.

\subsection{Analysis}

The present study examined changes in response of the RADUETs and the AlphaGUARD to thoron with respect to wind speed in the thoron calibration chamber. Response to thoron was defined as values indicated by the RADUETs or AlphaGUARD divided by thoron concentration in the air surrounding the detectors. The value indicated by each RADUET represented density of tracks formed on CR-39 and that indicated by the AlphaGUARD represented "radon" concentration. Based on these definitions, responses to thoron for the RADUETs $\left(R_{R}\right)$ and AlphaGUARD $\left(R_{\mathrm{A}}\right)$ were formulated as follows:

$$
R_{\mathrm{R}}=\frac{N_{\mathrm{ex}}-N_{\mathrm{bg}}}{C_{\text {Tn, out }} \times T}
$$




$$
R_{\mathrm{A}}=\frac{C_{\mathrm{ex}}-C_{\mathrm{bg}}}{C_{\mathrm{Tn}, \text { out }}}
$$

where $C_{\mathrm{Tn} \text {, out }}$ is thoron concentration in the thoron calibration chamber, $N_{\text {ex }}$ is track density after exposure to thoron is completed, $N_{\text {bg }}$ is background track density obtained from the control detectors, $T$ is exposure time, $C_{e x}$ is concentration indicated by the AlphaGUARD during exposure to thoron, and $C_{b g}$ is background radon concentration. The response of the RADUETs to thoron shown by Equation (3) can be regarded as a conversion coefficient for exposure to thoron for a CR-39 of the high diffusion rate chamber of the RADUET, and the response of the AlphaGUARD shown in Equation (4) can be regarded as a thoron entry rate described in previous studies (e.g., $[17,26,30,31])$.

The response to thoron for the detectors can be linked to their air exchange rate. Temporal variation of thoron concentration in a diffusion chamber is formulated as a derivative form with respect to time $t$ :

$$
\frac{d C_{\mathrm{Tn}, \text { in }}}{d t}=-\lambda C_{\mathrm{Tn}, \text { in }}+\gamma\left(C_{\mathrm{Tn}, \text { out }}-C_{\mathrm{Tn}, \text { in }}\right)
$$

where $C_{\mathrm{Tn} \text {, in }}$ and $C_{\mathrm{Tn} \text {, out }}$ are thoron concentrations in the diffusion chamber of the detector and thoron calibration chamber, respectively, and $\lambda$ is the decay constant $\left(44.9 \mathrm{~h}^{-1}\right)$ of thoron [31,32]. When enough time has passed for the thoron concentration to reach equilibrium, the ratio of thoron concentrations in the diffusion chamber to the thoron calibration chamber is a function of the air exchange rate and the decay constant of thoron, and it is formulated as:

$$
\frac{C_{\text {Tn, in }}}{C_{\text {Tn, out }}}=\frac{\gamma}{\lambda+\gamma} .
$$

The ratio can be related to the response of the detectors to thoron and, therefore, the air exchange rate.

\section{Results}

Figure 3 shows typical temporal variations in thoron concentration $\left(C_{\mathrm{Tn} \text {, out }}\right)$ in the thoron calibration chamber during the exposures of the RADUETs and the AlphaGUARD to thoron. In Figure $3 b$, the $C_{\text {ex }}$ and the $C_{b g}$ values indicated by the AlphaGUARD are presented together with the thoron concentrations. Time-integrated thoron concentration $\left(C_{\mathrm{Tn} \text {, out }} \times T\right)$ depicted in Figure $3 a$ was used to evaluate the response of the RADUETs to thoron expressed in Equation (3). In addition, averages of $C_{\mathrm{ex}}, C_{\mathrm{bg}}$, and $C_{\mathrm{Tn} \text {, out }}$ depicted in Figure $3 \mathrm{~b}$ were used to evaluate the response of the AlphaGUARD to thoron expressed in Equation (4).

Table 2 shows the results of exposure of the RADUETs and the AlphaGUARD to thoron under variable wind speeds in the thoron calibration chamber. The relationships between wind speed and the responses of the detectors to thoron are also shown in Figure 4. It is noted again that wind speed was measured in the thoron calibration chamber without setting the RADUETs or the AlphaGUARD in it. It is clearly seen from Figure 4 that the responses to thoron depended on wind speed for both types of detectors, but their trends were different. For the RADUETs, the response to thoron increased with wind speed (Figure 4a). This meant that air exchange was enhanced between the inside and the outside of the RADUETs, and the rate of thoron entry into their diffusion chambers increased with the increase in wind speed. For the AlphaGUARD, the response to thoron increased with wind speed at the very low to reference fan speed levels, which was similar to the trend of the RADUETs. However, it appeared to be constant above the reference fan speed (Figure 4b). In this range, air exchange was insensitive to the change in wind speed of the air surrounding the detector, and the rate of thoron entry into the detector diffusion chamber did not vary. These different trends between the RADUETs and the AlphaGUARD could possibly be attributed to properties of the filter/sponge covering the detector inlets. 


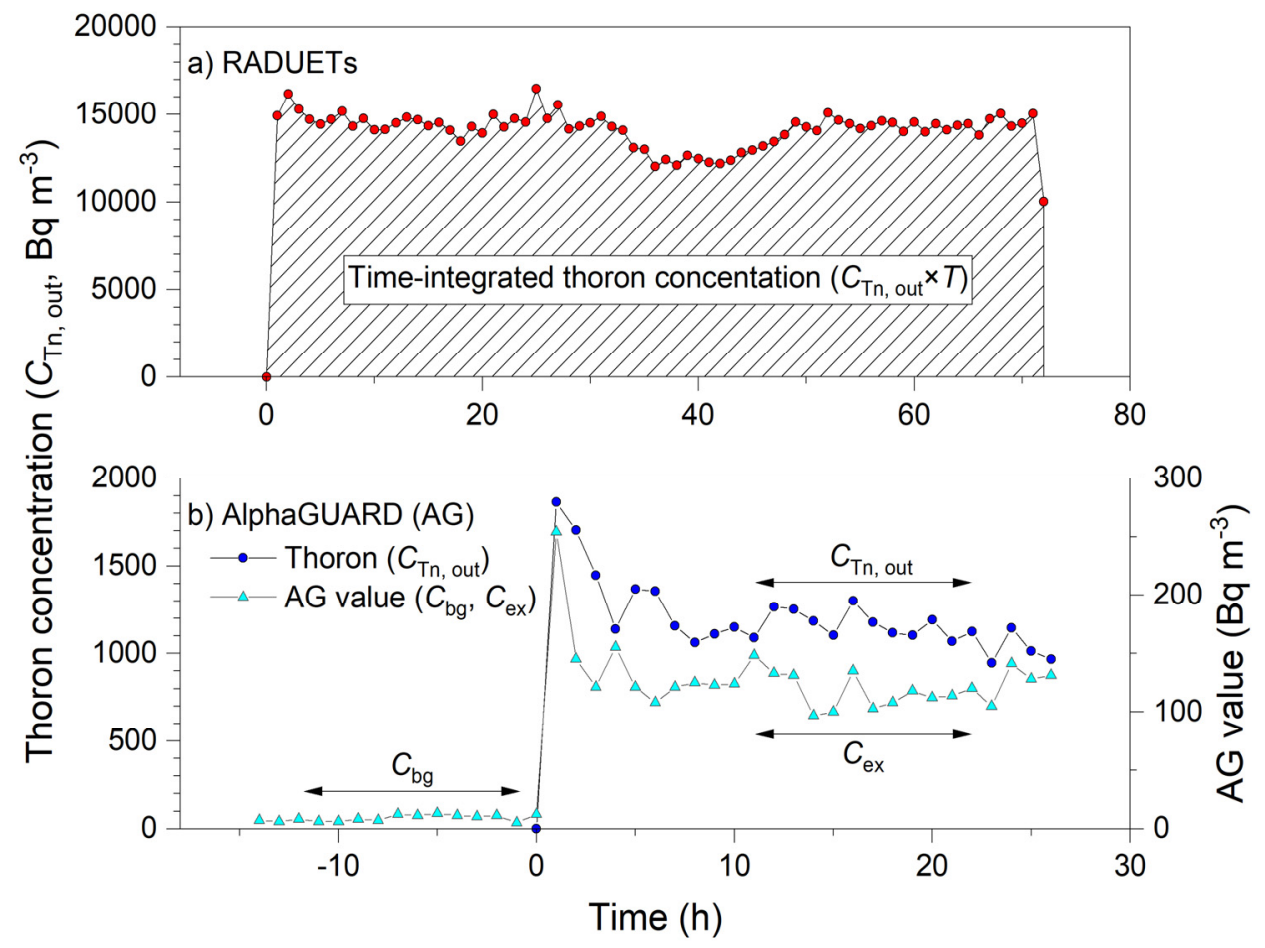

Figure 3. Examples of temporal variations in thoron concentration in the thoron calibration chamber during exposures of the RADUETs (a) and the AlphaGUARD (b) to thoron. In (b), values indicated by the AlphaGUARD are also shown. Meanings of symbols are the same as those in Equations (3) and (4).

Table 2. Results of exposure of RADUETs and AlphaGUARD to thoron under variable wind speeds in the thoron calibration chamber.

\begin{tabular}{|c|c|c|c|c|c|}
\hline RADUETs & & & & & \\
\hline $\begin{array}{l}\text { Wind Speed } \\
\quad\left(\mathrm{m} \mathrm{s}^{-1}\right)\end{array}$ & $\begin{array}{c}\text { Exposure Time } \\
(T, \mathrm{~h})\end{array}$ & $\begin{array}{c}\text { Time-Integrated Thoron } \\
\text { Concentration } \\
\left(C_{\mathrm{Tn}, \text { out }} \times T, \mathrm{kBq} \mathrm{m}^{-3} \mathrm{~h}\right)\end{array}$ & \multicolumn{2}{|c|}{$\begin{array}{c}\text { Net Track Density } \\
\left(N_{\text {ex }}-N_{\text {bg }}, \text { tracks } \mathrm{mm}^{-2}\right)^{1}\end{array}$} & $\begin{array}{l}\text { Response to } \\
\text { Thoron }\left(R_{\mathrm{R}}\right. \\
\text { tracks } \mathrm{mm}^{-2} \\
\left.\left(\mathrm{kBq} \mathrm{m}^{-3} \mathrm{~h}\right)^{-1}\right)\end{array}$ \\
\hline 0.27 & 71 & 1082 & \multicolumn{2}{|c|}{$12.6 \pm 1.3$} & $0.012 \pm 0.001$ \\
\hline 0.59 & 82 & 1281 & \multicolumn{2}{|c|}{$24.6 \pm 1.8$} & $0.019 \pm 0.001$ \\
\hline 0.85 & 72 & 1016 & \multicolumn{2}{|c|}{$19.7 \pm 0.5$} & $0.019 \pm 0.001$ \\
\hline 1.92 & 87 & 1007 & \multicolumn{2}{|c|}{$24.0 \pm 0.7$} & $0.024 \pm 0.001$ \\
\hline \multicolumn{6}{|l|}{ AlphaGUARD } \\
\hline \multirow{2}{*}{$\begin{array}{l}\text { Wind Speed } \\
\quad\left(\mathrm{m} \mathrm{s}^{-1}\right)\end{array}$} & \multirow{2}{*}{$\begin{array}{c}\text { Exposure Time } \\
(T, h)\end{array}$} & \multirow{2}{*}{ 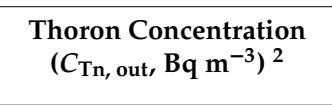 } & \multicolumn{2}{|c|}{ AlphaGUARD Value $\left(\mathrm{Bq} \mathrm{m}^{-3}\right)^{2}$} & \multirow{2}{*}{$\begin{array}{l}\text { Response to } \\
\text { Thoron }\left(R_{\mathrm{A}}\right)\end{array}$} \\
\hline & & & $C_{\mathrm{ex}}$ & $C_{\mathrm{bg}}$ & \\
\hline 0.27 & 21 & $12752 \pm 359$ & $549 \pm 42$ & $11 \pm 3$ & $0.042 \pm 0.004$ \\
\hline 0.59 & 17 & $12294 \pm 323$ & $816 \pm 37$ & $11 \pm 3$ & $0.065 \pm 0.003$ \\
\hline 0.85 & 16 & $932 \pm 80$ & $98 \pm 12$ & $4 \pm 2$ & $0.101 \pm 0.016$ \\
\hline 0.85 & 17 & $1049 \pm 65$ & $89 \pm 9$ & $8 \pm 3$ & $0.078 \pm 0.011$ \\
\hline 0.85 & 20 & $12254 \pm 680$ & $900 \pm 50$ & $11 \pm 3$ & $0.073 \pm 0.006$ \\
\hline 1.92 & 12 & $1165 \pm 76$ & $115 \pm 13$ & $9 \pm 3$ & $0.091 \pm 0.013$ \\
\hline 1.92 & 15 & $1014 \pm 117$ & $94 \pm 9$ & $10 \pm 3$ & $0.083 \pm 0.013$ \\
\hline
\end{tabular}

${ }^{1}$ Average value \pm one standard deviation obtained from five detectors. ${ }^{2}$ Average value \pm one standard deviation obtained from 12 to 21 datapoints in successive time series. 

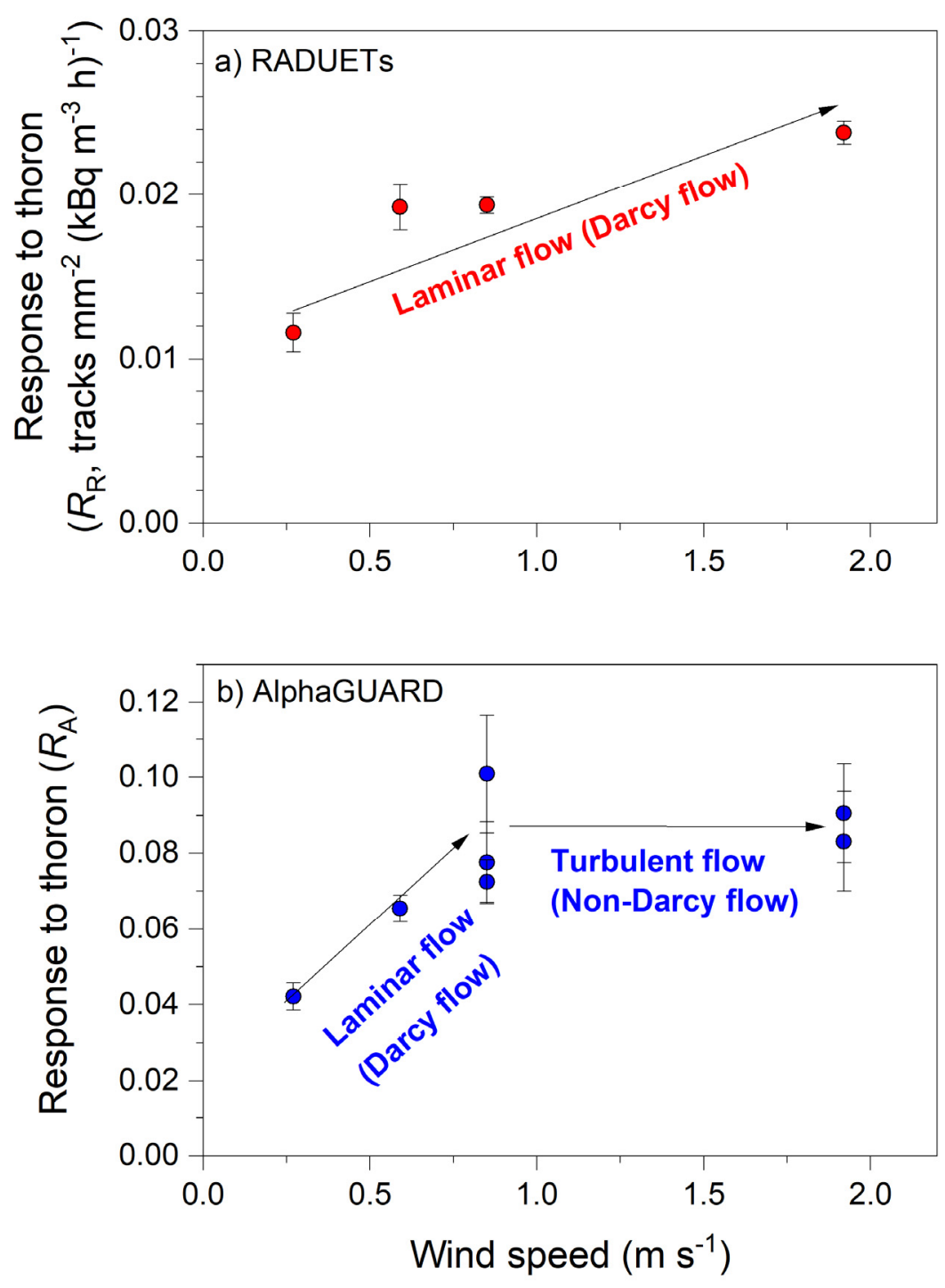

Figure 4. Scatter plots of responses of the RADUETs (a) and the AlphaGUARD (b) to thoron with respect to wind speed in the thoron calibration chamber. Bars on datapoints represent ranges of one standard deviation.

\section{Discussion}

The response to thoron (therefore, the air exchange rate) for the RADUETs and the AlphaGUARD varied with wind speed in the thoron calibration chamber. Different trends in the response to thoron with respect to wind speed were seen between these two detectors (Figure 4). Equations (1) and (2) imply that detector geometry (the inlet area divided by the detector volume) affects the air exchange rate, but this geometry value was similar between the RADUETs and the AlphaGUARD $\left(5.7 \mathrm{~m}^{-1}\right.$ vs. $6.3 \mathrm{~m}^{-1}$, respectively). The occurrence of the different trends was caused by properties of the filter/sponge. Visual observations showed that the sponge covering the inlet of the RADUETs was more porous than the filter covering that of the AlphaGUARD. In fact, the air exchange rate of the RADUETs was $10 \mathrm{~h}^{-1}$ [25], 2.5 times higher than that $\left(4 \mathrm{~h}^{-1}\right)$ of the AlphaGUARD, which was based on the assumption that the response to thoron was 0.10 of the actual thoron concentration. These findings implied that flow dynamics probably differed between the porous media of the filter and sponge.

Flow of fluids (including gases) in porous media is classified according to the degree of deviation from Darcy's law (e.g., [36-40]). Darcy's law states that the specific discharge is proportional to the pressure gradient for flow through a porous medium. This relationship holds in a certain range of 
pressure gradient where viscous force is dominant, and laminar (Darcy) flow is maintained. Outside this certain pressure gradient range, specific discharge deviates from that predicted by Darcy's law. In particular, in a higher pressure gradient range, inertial force becomes dominant and flow changes from laminar to turbulent (non-Darcy) flow. In this situation, the change of the pressure gradient has less impact on specific discharge compared to the impact in the case of laminar flow. Figure 5 shows a schematic representation of flow regimes in a porous medium.

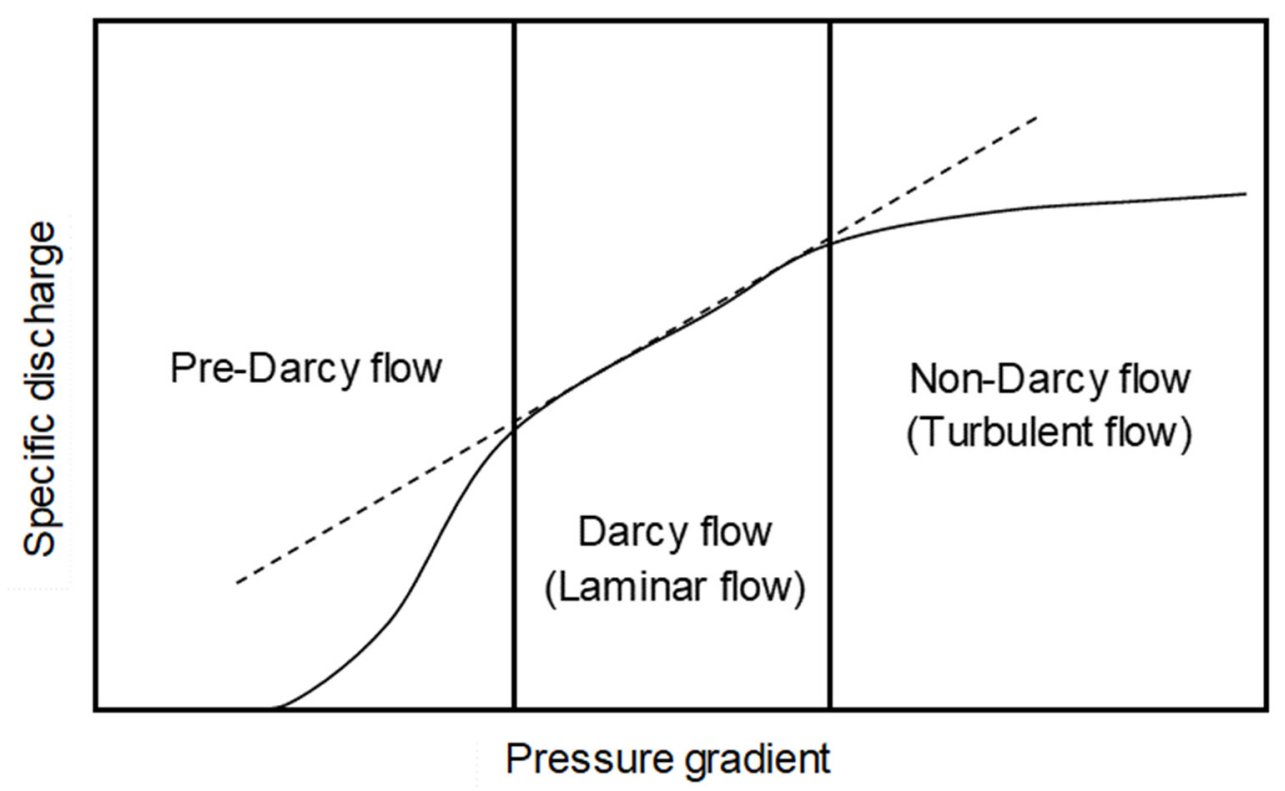

Figure 5. Schematic representation of flow regimes in a porous medium. The broken line follows Darcy's law. This figure is modified from Basak [37] and Macini et al. [40].

The different trends of the responses to thoron between the RADUETs and the AlphaGUARD can be qualitatively explained in flow regimes in a porous medium. Similar to the representations in Figure 5, specific discharge and pressure gradient are related to the response of the detectors to thoron and the wind field surrounding them, respectively. If wind speed is higher, pressure loss and, therefore, pressure gradient would be higher due to the presence of the filter or sponge. For the RADUETs, the response to thoron increased with wind speed (Figure 4a), which implies that thoron entry into the detectors was constrained by laminar (Darcy) flow induced in the sponge in the examined wind speed range. On the other hand, the response to thoron for the AlphaGUARD increased with wind speed, but it became constant at higher wind speed (Figure $4 \mathrm{~b}$ ). These different trends at lower and higher wind speeds imply that flow regimes for thoron entry into the detector changed from laminar flow to turbulent (non-Darcy) flow in the examined wind speed range. Visual observations showed that the filter of the AlphaGUARD was denser than the sponge in the RADUETs. The denser filter would have a significant impact on the pressure loss caused by the wind field surrounding the detectors. The present study suggests that flow regimes in the filter or the sponge covering the inlet of the detectors play an important role in the changes of the response to thoron with respect to wind field.

Wind direction toward the air inlet(s) of the detectors may affect thoron entry into them. In the present study, because of the limited space of the small thoron calibration chamber, the wind measurement could not be conducted simultaneously with exposure of the detectors to thoron, thus actual wind speed and direction were not determined. Regarding thoron entry into the RADUETs, the influence of wind direction is considered to be small because the six air inlets are spaced equally in the cylindrical side wall of the RADUETs (Figure 1a). However, regarding the AlphaGUARD, wind direction may influence thoron entry into the detector because the air inlet exists only on one side (Figure $1 b$ ). The present study showed that the response of the AlphaGUARD to thoron was from $0.04 \pm 0.00(0.042 \pm 0.004)$ to $0.10 \pm 0.02(0.101 \pm 0.016)$ in the examined wind speed range in the thoron 
calibration chamber (Table 2$)$. The obtained values were comparable to those $(0.05-0.10)$ reported in previous studies (e.g., [17,26,30,31]). Omori et al. [26] reported that the distribution (0.00-0.30; median, 0.06 ) of the response to thoron in natural air ventilation (wind speed: about $0.03 \mathrm{~m} \mathrm{~s}^{-1}$ ) was wider than that (0.05-0.23; median, 0.11 ) in forced air ventilation (wind speed: $0.12 \mathrm{~m} \mathrm{~s}^{-1}$ ) in the underfloor-space air of a Japanese dwelling because of exposure to low thoron concentration $\left(10-100 \mathrm{~Bq} \mathrm{~m}^{-3}\right)$ with diurnal fluctuations. Unlike that study [26], the present study used the thoron calibration chamber to realize and maintain a high thoron concentration (1000-10,000 $\mathrm{Bq} \mathrm{m}^{-3}$; Figure 3 and Table 2), which led to lowered uncertainty of the experimental results. There also appears to be a discrepancy in the response to thoron per wind speed between the present study and Omori et al. [26]. The present study evaluated the response as $0.07-0.10$ at wind speed of $0.85 \mathrm{~m} \mathrm{~s}^{-1}$, whereas Omori et al. [26] obtained 0.11 at wind speed of $0.13 \mathrm{~m} \mathrm{~s}^{-1}$. This is possibly because, in the present study, wind measurement in the thoron calibration chamber was made without setting the AlphaGUARD in it and, therefore, the actual wind speed during the exposure was expected to be lower than $0.85 \mathrm{~m} \mathrm{~s}^{-1}$. Another possible reason is the different wind fields between these two studies. The wind flowed against the air inlet of the AlphaGUARD in Omori et al. [26], whereas the wind was not necessarily against but rather was circulated by the DC fan in the thoron calibration chamber in the present study. Either or both of these factors might cause the discrepancy.

The findings in the present study provide insights into measurement of thoron using diffusion-type thoron detectors. The present study revealed that the response of the detectors (in particular, the RADUETs) to thoron varied depending on wind speed. This finding does not indicate that the conversion coefficient from track density formed on CR-39 to time-integrated thoron concentration is stable in the environment with a widely variable wind field. It is expected that different conversion coefficients should be given between indoor and outdoor environments and maybe even between indoor rooms with different ventilation rates of the inner air. Use of the single conversion coefficient value causes increased uncertainty in thoron evaluation, which partly leads to increased uncertainty of the radon evaluation corrected by thoron as described above. Therefore, it is necessary to clarify the distribution of the conversion coefficient in the real (natural) living environment.

The present study also provides insights into calibration and intercomparison processes for diffusion-type thoron detectors. Thoron detectors are calibrated in the atmosphere with a known thoron concentration, which is produced, for example, in thoron calibration chambers (e.g., [33,41-44]). Intercomparison exercises are also important for quality assurance and quality control of thoron detectors (e.g., [44-47]). An international intercomparison exercise on diffusion-type thoron detectors reported that various thoron concentrations presented by detectors provided by the exercise participants and those relative to the reference thoron concentration were distributed widely from 0.2 to 1.5 [46]. Occurrence of the difference would be natural in part if the participants' detectors were calibrated under a wind field that was different from that in the thoron calibration chamber of the intercomparison exercise host. That is, the conversion coefficients can differ even for the same detectors exposed to thoron at the same concentration level if calibration conditions used for calibration of the detectors are not the same. Although various factors can be considered, different specifications of thoron calibration facilities among participants' laboratories can be raised as a potential factor for the cause of the difference.

Some studies reported differences in thoron concentration obtained from simultaneous measurements in environments (dwellings and subsurface workplace) using different diffusion-type thoron detectors (e.g., [48,49]). The above discussion suggested that variable conversion coefficients depending on wind field and different specifications of thoron calibration facilities used for calibration of the detectors may cause part of the reported differences.

\section{Conclusions}

The present study reported variations in responses of two diffusion-type radon and thoron detectors, RADUETs and AlphaGUARD, to thoron under variable wind fields in the thoron calibration 
chamber. The response of RADUETs to thoron increased with wind speed, which implied that advection in the state of laminar (Darcy) flow caused thoron entry into the detector. In contrast, the response of the AlphaGUARD increased with wind speed, but it became constant at high wind speed. This different trend implied that flow regimes for thoron entry into the detector changed from laminar flow to turbulent (non-Darcy) flow. The finding that the responses of the detectors to thoron varied depending on wind field should provide insights into improving measurement of thoron and processes of quality assurance and quality control for diffusion-type thoron detectors.

Author Contributions: Conceptualization, Y.O., M.H. and S.T.; methodology, Y.O., M.H. and S.T.; validation, Y.O., Y.T., E.D.N. and T.S.; formal analysis, Y.O., Y.T., E.D.N. and T.S.; investigation, Y.O., Y.T., E.D.N., T.S. and M.A.S.; resources, Y.O. and S.T.; data curation, Y.O., Y.T. and E.D.N.; writing-original draft preparation, Y.O. and Y.T.; writing - review and editing, Y.O., Y.T., E.D.N., T.S., M.A.S., M.H. and S.T.; visualization, Y.O.; supervision, Y.O. and S.T.; project administration, Y.O., Y.T. and T.S.; funding acquisition, Y.O. All authors have read and agreed to the published version of the manuscript.

Funding: This research was funded by Fukushima Medical University (KKI27024), the JSPS Grant-in-Aid for Early-Career Scientists (JP18K13620) and the Environmental Radioactivity Research Network Center (HY-18-3 and Y-19-18).

Acknowledgments: The authors would like to thank M. Ikeda for her support to prepare and process RADUETs. The present article was improved by valuable and constructive comments from reviewers.

Conflicts of Interest: The authors declare no conflict of interest.

\section{Abbreviations}

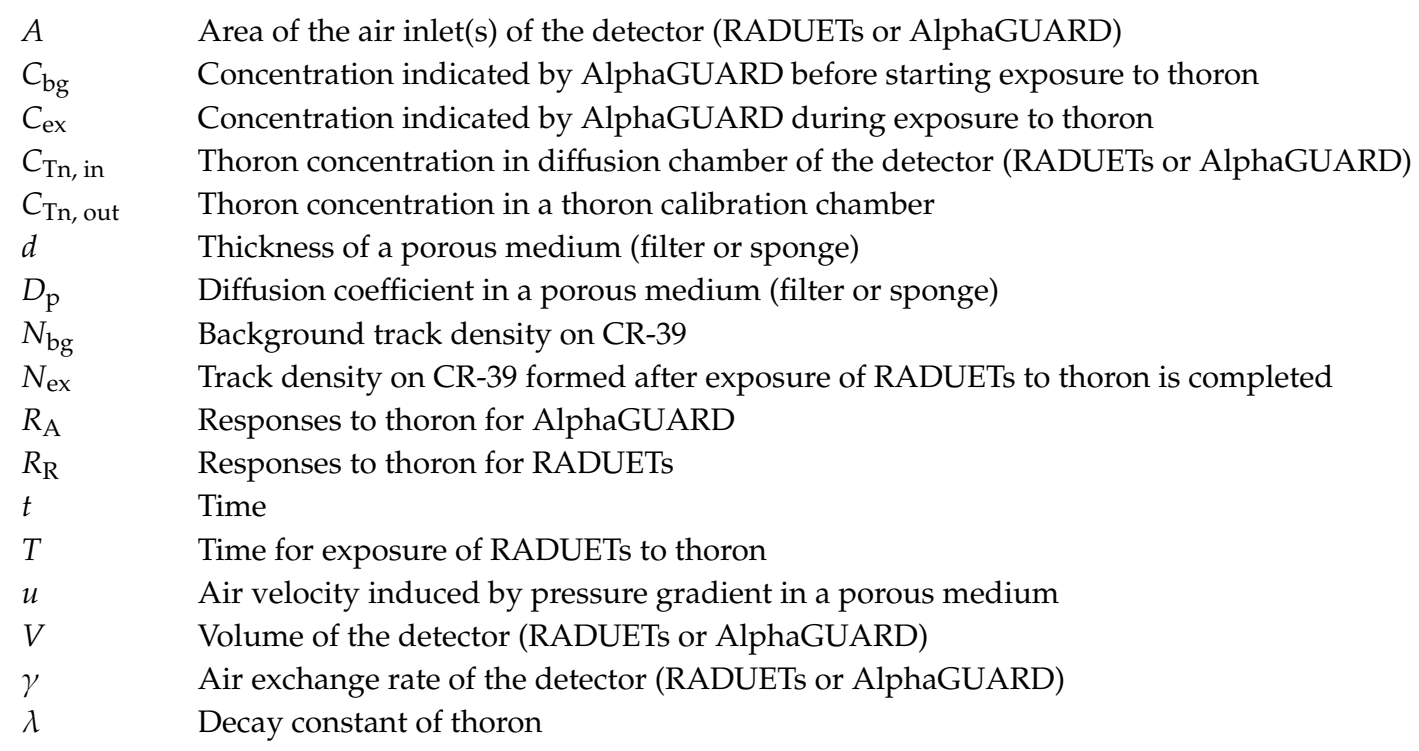

\section{References}

1. United Nations Scientific Committee on the Effects of Atomic Radiation (UNSCEAR). Sources and Effects of Ionizing Radiation, UNSCEAR 2008 Report to the General Assembly with Scientific Annexes; United Nations: New York, NY, USA, 2010; Volume 1.

2. Omori, Y.; Hosoda, M.; Takahashi, F.; Sanada, T.; Hirao, S.; Ono, K.; Furukawa, M. Japanese population dose from natural radiation. J. Radiol. Prot. 2020, in press. [CrossRef] [PubMed]

3. Porstendörfer, J. Properties and behaviour of radon and thoron and their decay products in the air. J. Aerosol Sci. 1994, 25, 219-263. [CrossRef]

4. United Nations Scientific Committee on the Effects of Atomic Radiation (UNSCEAR). Sources and Effects of Ionizing Radiation, UNSCEAR 2000 Report to the General Assembly with Scientific Annexes; United Nations: New York, NY, USA, 2000; Volume 1.

5. World Health Organization (WHO). WHO Handbook on Indoor Radon: A Public Health Perspective; WHO: Geneva, Switzerland, 2009. 
6. International Commission on Radiological Protection (ICRP). Radiological Protection against Radon Exposure. ICRP Publication 126. Annals of the ICRP 43(3); SAGE Publications: London, UK, 2014.

7. Hosoda, M.; Kudo, H.; Iwaoka, K.; Yamada, R.; Suzuki, T.; Tamakuma, Y.; Tokonami, S. Characteristic of thoron $\left({ }^{220} \mathrm{Rn}\right)$ in environment. Appl. Radiat. Isot. 2017, 120, 7-10. [CrossRef] [PubMed]

8. Chen, J.; Harley, N.H. A review of indoor and outdoor radon equilibrium factors-part I: ${ }^{222}$ Rn. Health Phys. 2018, 115, 490-499. [CrossRef]

9. Chen, J.; Harley, N.H. A review of indoor and outdoor radon equilibrium factors-part II: ${ }^{220}$ Rn. Health Phys. 2018, 115, 500-506. [CrossRef]

10. Tokonami, S.; Sun, Q.; Akiba, S.; Zhuo, W.; Furukawa, M.; Ishikawa, T.; Hou, C.; Zhang, S.; Narazaki, Y.; Ohji, B.; et al. Radon and thoron exposures for cave residents in Shanxi and Shaanxi Provinces. Radiat. Res. 2004, 162, 390-396. [CrossRef]

11. Kudo, H.; Tokonami, S.; Omori, Y.; Ishikawa, T.; Iwaoka, K.; Sahoo, S.K.; Akata, N.; Hosoda, M.; Wanabongse, P.; Pornnumpa, C.; et al. Comparative dosimetry for radon and thoron in high background radiation areas in China. Radiat. Prot. Dosim. 2015, 167, 155-159. [CrossRef]

12. Omori, Y.; Prasad, G.; Sorimachi, A.; Sahoo, S.K.; Ishikawa, T.; Sagar, D.V.; Ramola, R.C.; Tokonami, S. Long-term measurements of residential radon, thoron, and thoron progeny concentrations around the Chhatrapur placer deposit, a high background radiation area in Odisha, India. J. Environ. Radioact. 2016, 162-163, 371-378. [CrossRef]

13. Omori, Y.; Tokonami, S.; Sahoo, S.K.; Ishikawa, T.; Sorimachi, A.; Hosoda, M.; Kudo, H.; Pornnumpa, C.; Nair, R.R.K.; Jayalekshmi, P.A.; et al. Radiation dose due to radon and thoron progeny inhalation in high-level natural radiation areas of Kerala, India. J. Radiol. Prot. 2017, 37, 111-126. [CrossRef]

14. Meisenberg, O.; Mishra, R.; Joshi, M.; Gierl, S.; Rout, R.; Guo, L.; Agarwal, T.; Kanse, S.; Irlinger, J.; Sapra, B.K.; et al. Radon and thoron inhalation doses in dwellings with earthen architecture: Comparison of measurement methods. Sci. Total Environ. 2017, 579, 1855-1862. [CrossRef]

15. Semwal, P.; Agarwal, T.K.; Singh, K.; Joshi, M.; Gusain, G.S.; Sahoo, B.K.; Ramola, R.C. Indoor inhalation dose assessment for thoron-rich regions of Indian Himalayan belt. Environ. Sci. Pollut. Res. 2019, 26, 4855-4866. [CrossRef] [PubMed]

16. Tokonami, S.; Yang, M.; Sanada, T. Contribution from thoron on the response of passive radon detectors. Health Phys. 2001, 80, 612-615. [CrossRef] [PubMed]

17. Ishikawa, T. Effects of thoron on a radon detector of pulse-ionization chamber type. Radiat. Prot. Dosim. 2004, 108, 327-330. [CrossRef] [PubMed]

18. Zhuo, W.; Tokonami, S.; Yonehara, H.; Yamada, Y. A simple passive monitor for integrating measurements of indoor thoron concentrations. Rev. Sci. Instrum. 2002, 73, 2877-2881. [CrossRef]

19. Tokonami, S.; Takahashi, H.; Kobayashi, Y.; Zhuo, W. Up-to-date radon-thoron discriminative detector for a large scale survey. Rev. Sci. Instrum. 2005, 76, 113505. [CrossRef]

20. Sahoo, B.K.; Sapra, B.K.; Kanse, S.D.; Gaware, J.J.; Mayya, Y.S. A new pin-hole discriminated ${ }^{222} \mathrm{Rn} /{ }^{220} \mathrm{Rn}$ passive measurement device with single entry face. Radiat. Meas. 2013, 58, 52-60. [CrossRef]

21. Ward, W.J., III; Fleischer, R.L.; Mogro-Campero, A. Barrier technique for separate measurement of radon isotopes. Rev. Sci. Instrum. 1977, 48, 1440-1441. [CrossRef]

22. Iida, T.; Nurishi, R.; Okamoto, K. Passive integrating ${ }^{222} \mathrm{Rn}$ and ${ }^{220} \mathrm{Rn}$ cup monitors with CR-39 detectors. Environ. Int. 1996, 22 (Suppl. 1), 641-647. [CrossRef]

23. Fleischer, R.L.; Giard, W.R.; Turner, L.G. Membrane-based thermal effects in ${ }^{222}$ Rn dosimetry. Radiat. Meas. 2000, 32, 325-328. [CrossRef]

24. Pressyanov, D.; Dimitrov, D. The problem with temperature dependence of radon diffusion chambers with anti-thoron barrier. Rom. J. Phys. 2020, 65, 801.

25. Sorimachi, A.; Tokonami, S.; Omori, Y.; Ishikawa, T. Performance test of passive radon-thoron discriminative detectors on environmental parameters. Radiat. Meas. 2012, 47, 438-442. [CrossRef]

26. Omori, Y.; Shimo, M.; Janik, M.; Ishikawa, T.; Yonehara, H. Variable strength in thoron interference for a diffusion-type radon monitor depending on ventilation of the outer air. Int. J. Environ. Res. Public Health 2020, 17, 974. [CrossRef] [PubMed]

27. Yasuoka, Y.; Sorimachi, A.; Ishikawa, T.; Hosoda, M.; Tokonami, S.; Fukuhori, N.; Janik, M. Separately measuring radon and thoron concentrations exhaled from soil using AlphaGUARD and liquid scintillation counter methods. Radiat. Prot. Dosim. 2010, 141, 412-415. [CrossRef] [PubMed] 
28. Tripathi, R.M.; Sumesh, C.G.; Vinod Kumar, A.; Puranik, V.D. Application of thoron interference as a tool for simultaneous measurement of radon and thoron with a pulse ionisation chamber. Radiat. Prot. Dosim. 2013, 155, 155-160. [CrossRef]

29. Jónás, J.; Sas, Z.; Vaupotic, J.; Kocsis, E.; Somlai, J.; Kovács, T. Thoron emanation and exhalation of Slovenian soils determined by a PIC detector-equipped radon monitor. Nukleonika 2016, 61, 379-384. [CrossRef]

30. Kochowska, E.; Kozak, K.; Kozłowska, B.; Mazur, J.; Dorda, J. Test measurements of thoron concentration using two ionization chambers AlphaGUARD vs. radon monitor RAD7. Nukleonika 2009, 54, 189-192.

31. Sumesh, C.G.; Vinod Kumar, A.; Tripathi, R.M.; Puranik, V.D. Comparison study and thoron interference test of different radon monitors. Radiat. Prot. Dosim. 2013, 153, 309-315. [CrossRef]

32. Omori, Y.; Janik, M.; Sorimachi, A.; Ishikawa, T.; Tokonami, S. Effects of air exchange property of passive-type radon-thoron discriminative detectors on performance of radon and thoron measurements. Radiat. Prot. Dosim. 2012, 152, 140-145. [CrossRef]

33. Pornnumpa, C.; Oyama, Y.; Iwaoka, K.; Hosoda, M.; Tokonami, S. Development of radon and thoron exposure systems at Hirosaki University. Radiat. Environ. Med. 2018, 7, 13-20.

34. Sorimachi, A.; Sahoo, S.K.; Tokonami, S. Generation and control of thoron emanated from lantern mantles. Rev. Sci. Instrum. 2009, 80, 015104. [CrossRef]

35. Tokonami, S.; Yang, M.; Yonehara, H.; Yamada, Y. Simple, discriminative measurement technique for radon and thoron concentrations with a single scintillation cell. Rev. Sci. Instrum. 2002, 73, 69-72. [CrossRef]

36. Lorenzi, A. Laminar, turbulent, and transition flow in porous sintered media. Meccanica 1975, 10, 75-77. [CrossRef]

37. Basak, P. Non-Darcy flow and its implications to seepage problems. J. Irrigation Drainage Div. 1977, 103, $459-473$.

38. Bear, J. Dynamics of Fluids in Porous Media; Dover Publications, Inc.: New York, NY, USA, 1988; pp. 119-194.

39. Belforte, G.; Raparelli, T.; Viktorov, V.; Trivella, A. Permeability and inertial coefficients of porous media for air bearing feeding systems. J. Tribol. 2007, 129, 705-711. [CrossRef]

40. Macini, P.; Mesini, E.; Viola, R. Laboratory measurements of non-Darcy flow coefficients in natural and artificial unconsolidated porous media. J. Petrol. Sci. Eng. 2011, 77, 365-374. [CrossRef]

41. Gargioni, E.; Honig, A.; Röttger, A. Development of a calibration facility for measurements of the thoron activity concentration. Nucl. Instrum. Meth. Phys. Res. A 2003, 506, 166-172. [CrossRef]

42. Sorimachi, A.; Ishikawa, T.; Janik, M.; Tokonami, S. Quality assurance and quality control for thoron measurement at NIRS. Radiat. Prot. Dosim. 2010, 141, 367-370. [CrossRef]

43. Zhao, C.; Zhuo, W.; Chen, B.; Zhang, H. Characteristic and performance of a simple thoron chamber. Radiat. Prot. Dosim. 2010, 141, 444-447. [CrossRef]

44. Jílek, K.; Hýža, M.; Kotík, L.; Thomas, J.; Tomášek, L. International intercomparison of measuring instruments for radon/thoron gas and radon short-lived daughter products in the NRPI Prague. Radiat. Prot. Dosim. 2014, 160, 154-159. [CrossRef]

45. Janik, M.; Tokonami, S.; Kranrod, C.; Sorimachi, A.; Ishikawa, T.; Hassan, N.M. International intercomparisons of integrating radon/thoron detectors with the NIRS radon/thoron chambers. Radiat. Prot. Dosim. 2010, 141, 436-439. [CrossRef]

46. Janik, M.; Ishikawa, T.; Omori, Y.; Kavasi, N. Invited article: Radon and thoron intercomparison experiments for integrated monitors at NIRS, Japan. Rev. Sci. Instrum. 2014, 85, 022001. [CrossRef] [PubMed]

47. Janik, M.; Tokonami, S.; Iwaoka, K.; Karunakara, N.; Trilochana, S.; Mohan, M.P.; Kumara, S.; Yashodhara, I.; Zhuo, W.; Zhao, C.; et al. Comparison of radon and thoron concentration measuring systems among Asian countries. Int. J. Environ. Res. Public Health 2019, 16, 5019. [CrossRef] [PubMed]

48. Szeiler, G.; Somlai, J.; Ishikawa, T.; Omori, Y.; Mishra, R.; Sapra, B.K.; Mayya, Y.S.; Tokonami, S.; Csordás, A.; Kovács, T. Preliminary results from an indoor radon thoron survey in Hungary. Radiat. Prot. Dosim. 2012, 152, 243-246. [CrossRef] [PubMed]

49. Kávási, N.; Vigh, T.; Németh, C.; Ishikawa, T.; Omori, Y.; Janik, M.; Yonehara, H. Invited article: In situ comparison of passive radon-thoron discriminative monitors at subsurface workplaces in Hungary. Rev. Sci. Instrum. 2014, 85, 022002. [CrossRef]

(C) 2020 by the authors. Licensee MDPI, Basel, Switzerland. This article is an open access article distributed under the terms and conditions of the Creative Commons Attribution (CC BY) license (http://creativecommons.org/licenses/by/4.0/). 